\title{
Leisure Pursuit Website Usability: An Equestrian Sport Case Study
}

\author{
Rebecca Wilkins ${ }^{1}$, Abel Nyamapfene ${ }^{2}$ \\ Webbased Ltd ${ }^{1}$, University of Exeter ${ }^{2}$, United Kingdom
}

\begin{abstract}
Equestrian sport is a popular leisure pursuit in the South West of England (i.e. Devon and Cornwall) and there are a number of event search websites, developed mainly on an amateur basis, that provide equestrian sports enthusiasts in the region with timely information. However, anecdotal evidence suggests that these websites are shunned in preference to traditional information sources such as newspapers, magazines and word of mouth. Given the widely acknowledged link between website usability and success, we hypothesise that poor usability may be a key factor in the lack of popularity of these websites. A heuristic evaluation of the three most popular equestrian sport websites in the region lends support to this hypothesis. On the basis of this heuristic evaluation, we propose a website development guideline that complies with standard usability principles. Subsequent user tests on a prototype search website built using this guideline suggest that improving the usability of the equestrian sport websites in the South West of England could result in an improvement in their popularity.
\end{abstract}

\section{Introduction}

The Internet has grown to such an extent that it is now part and parcel of everyday life, especially in developed countries like the UK. For instance, within the UK Internet penetration has reached such an extent that by the year 2009 73\% of UK households had access to the Internet [1]. Concomitant with this high penetration value, the Internet has become a prime source of information with people generally using the Internet as the first port of call when looking for information for both work-related and personal needs [2].

As the Internet has become more central in people's lives, websites dedicated to providing information for leisure pursuits have proliferated. One such leisure pursuit is equestrian sport, which is very popular in the South West of England (i.e. Devon and Cornwall) where, on average, 20 equestrian sport events take place each week with average attendances of 200 people per event. Such high attendances point to a vibrant, well-defined audience, and entrepreneurs have been quick to develop websites to cater for the information needs of equestrian sport enthusiasts in and around Devon and Cornwall.
However, despite the proliferation of equestrian sport websites in Devon and Cornwall, the sport remains dominated by traditional information sources such as newspapers, magazines, leaflets and word of mouth. Informal surveys carried out by the authors suggest that the majority of people generally find the available websites to be overly complex, inadequate and user-unfriendly. Given this scenario, the key research question, which we attempt to address in this paper, is: Are equestrian sport websites in Devon and Cornwall meeting the usability requirements of their intended audience? In this case the term usability refers to the ease with which the target user can learn and memorise a site's basic functions; the efficiency of design of the site; the degree of error avoidance incorporated within the site's design and the general satisfaction of the user [3]. The question is important because poor usability presents access challenges to prospective users, thereby leading to reduced flows of traffic to the website, which, in turn, reduces the number of people and organisations wishing to advertise on the website, thereby making the website a commercial failure.

This paper is organised as follows: Section 2 gives an overview of usability in website development and includes a discussion of the methods used to assess the usability of websites. In Section 3 we report on our evaluation of equestrian sport websites in Devon and Cornwall whilst in Section 4 we propose guidelines for equestrian sport website development. These guidelines follow directly from our website evaluation in Section 3. We then present, in Section 5, a prototype website built using our proposed guidelines, and discuss our usability evaluation of the prototype using test participants drawn from equestrian sports enthusiasts in Devon and Cornwall. Finally, we conclude the paper by highlighting the importance of usability and user centred design principles in the design and implementation of leisure pursuit websites, including equestrian sport websites.

\section{An Overview of Website Usability}

According to the ISO9241 [4], the usability of a product is "the extent to which the product can be used by specified users to achieve specified goals 
with effectiveness, efficiency and satisfaction in a specified context of use" where:

- Effectiveness refers to the accuracy and completeness with which users achieve specified goals.

- Efficiency is a measure of the resources expended by the users in relation to their effectiveness in achieving their goals. Relevant resources can include mental or physical effort, time, materials or financial cost.

- Satisfaction refers to the extent to which users are free from discomfort, and their attitudes towards the use of the product.

- Context of use refers to the users, tasks, equipment (hardware, software and materials), and the physical and social environments in which a product is used.

The intended usability of a product is only achieved if usability considerations are incorporated at all stages of the product design and implementation cycle. ISO9241 facilitates this process by including guidance for specifying the usability requirements of a product in terms of its intended goals, context of use as well as the measures of effectiveness, efficiency and satisfaction to be used. The test conditions and evaluation criteria that will be used to assess the usability of the product are also developed during the planning and design process.

Shneiderman [5] has identified the key usability requirements of user interfaces and distilled them down into a set of eight rules commonly referred to as the eight golden rules. These rules, which can be used as guidelines for developing websites, are as follows:

1. Strive for consistency.

2. Enable frequent users to use shortcuts.

3. Offer informative feedback.

4. Design dialogues to yield closure.

5. Offer error prevention and simple error handling.

6. Permit easy reversal of actions.

7. Support internal locus of control.

8. Reduce short-term memory load

The usability of a website can be assessed through usability inspection and/or user-based evaluation. Usability inspection refers to the set of methods whereby evaluators inspect a user interface to assess its usability [3]. In contrast, in user-based evaluation methods usability is evaluated by observing users interacting with the interface and noting their comments. Typically, usability inspection methods are more cost-effective than user-based evaluation methods and are often better suited to project schedules. However Nielsen [3] suggests that the two approaches should be viewed as complementary and should ideally be used in combination since they are each suited to identifying different usability problems.

Examples of usability inspection include heuristic evaluation and cognitive walkthrough [5]. In cognitive walkthrough a group of evaluators compiles a set of tasks that must be implemented to achieve specific user goals using a given interface. The group of evaluators then steps through each of the tasks, identifying at each step of the task any difficulties a user might experience. Cognitive walkthrough is especially relevant in evaluating the usability of an interface for inexperienced users.

In heuristic evaluation evaluators individually assess the given interface against a set of usability principles, commonly referred to as the "heuristics" [3], and then compare notes to agree on a common evaluation. Compared to other usability inspection methods, heuristic evaluation is fast, cheap, easy to learn and effective [6]. Nielsen [7] has compiled a set of ten heuristics that are generally applicable across all user interface designs (Table 1). We shall use heuristic evaluation in our assessment of Devon and Cornwall equestrian sport websites.

\section{Usability Analysis of Three Equestrian Sport Websites}

We have identified the three most popular equestrian sport websites in Devon and Cornwall and assessed their usability using heuristic evaluation in an attempt to provide an answer to the question: Are equestrian sport websites in Devon and Cornwall meeting the usability requirements of their intended audience? The three websites are Web South West [8], Equine Tourism [9] and The Riding Diary [10]. As suggested by our discussions with equestrian sports enthusiasts in and around Devon and Cornwall, the Web South West website appears to be, by far, the most popular equestrian sport website. 
Table 1. Nielsen set of ten heuristics for evaluating usability [7]

\begin{tabular}{|c|c|}
\hline Heuristic & Explanation \\
\hline Visibility of system status & $\begin{array}{l}\text { The system should always keep users informed about what is going on, through appropriate } \\
\text { feedback within reasonable time. }\end{array}$ \\
\hline $\begin{array}{l}\text { Match between system and the real } \\
\text { world }\end{array}$ & $\begin{array}{l}\text { The system should speak the users' language, with words, phrases and concepts familiar to the } \\
\text { user, rather than system-oriented terms. Follow real-world conventions, making information } \\
\text { appear in a natural and logical order. }\end{array}$ \\
\hline User control and freedom & $\begin{array}{l}\text { Users often choose system functions by mistake and will need a clearly marked "emergency } \\
\text { exit" to leave the unwanted state without having to go through an extended dialogue. Support } \\
\text { undo and redo. }\end{array}$ \\
\hline Consistency and standards & $\begin{array}{l}\text { Users should not have to wonder whether different words, situations, or actions mean the same } \\
\text { thing. Follow platform conventions. }\end{array}$ \\
\hline Error prevention & $\begin{array}{l}\text { Even better than good error messages is a careful design which prevents a problem from } \\
\text { occurring in the first place. Either eliminate error-prone conditions or check for them and } \\
\text { present users with a confirmation option before they commit to the action. }\end{array}$ \\
\hline Recognition rather than recall & $\begin{array}{l}\text { Minimize the user's memory load by making objects, actions, and options visible. The user } \\
\text { should not have to remember information from one part of the dialogue to another. Instructions } \\
\text { for use of the system should be visible or easily retrievable whenever appropriate. }\end{array}$ \\
\hline Aesthetic and minimalist design & $\begin{array}{l}\text { Dialogues should not contain information which is irrelevant or rarely needed. Every extra unit } \\
\text { of information in a dialogue competes with the relevant units of information and diminishes } \\
\text { their relative visibility. }\end{array}$ \\
\hline $\begin{array}{l}\text { Help users recognize, diagnose, } \\
\text { and recover from errors }\end{array}$ & $\begin{array}{l}\text { Error messages should be expressed in plain language (no codes), precisely indicate the } \\
\text { problem, and constructively suggest a solution. }\end{array}$ \\
\hline Help and documentation & $\begin{array}{l}\text { Even though it is better if the system can be used without documentation, it may be necessary } \\
\text { to provide help and documentation. Any such information should be easy to search, focused on } \\
\text { the user's task, list concrete steps to be carried out, and not be too large. }\end{array}$ \\
\hline
\end{tabular}

\subsection{The Web South West Website}

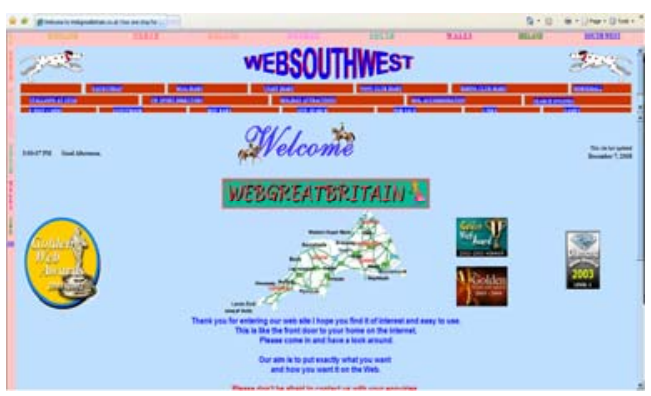

Figure 1. The Web South West Homepage

The Web South West website [Figure 1] allows users to look up horse events and competitions whilst also offering other facilities such as holiday attractions and classified links. Positive aspects for this site are that the layout of web pages is fairly consistent throughout the site, and the visibility and clarity of web pages have been enhanced by appropriate use of white space. However, the website lacks a clearly defined content structure which tends to confuse site users, especially those who are new to the site. This is further compounded by the lack of help facilities which makes the website particularly challenging for novice users.

Navigational links and a search facility have been used as the primary methods for information access. The site uses terms and acronyms that are easily understood by equestrian sport enthusiasts as link titles. Whilst this makes the website user-friendly, the lack of supporting information to guide navigation and search makes it difficult for users who are not familiar with the site.

\subsection{The Riding Diary Website}

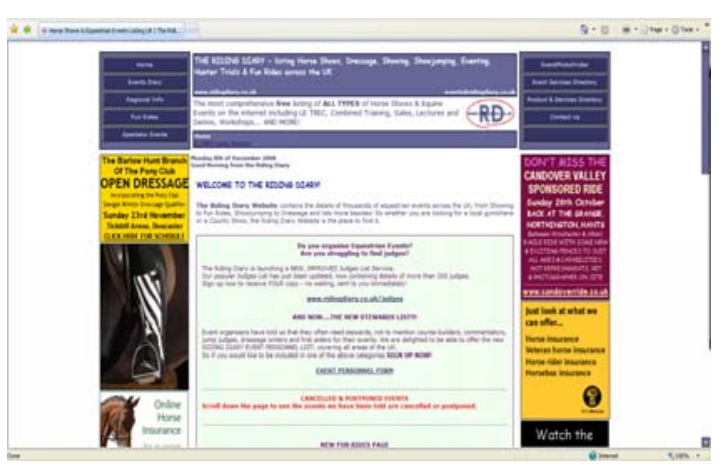

Figure 2. The Riding Diary Homepage 
Table 2. Qualitative Results for the Heuristic Evaluation of the Web South West Website

\begin{tabular}{|c|c|c|}
\hline \multirow[t]{2}{*}{ Heuristics } & \multicolumn{2}{|c|}{ Web South West } \\
\hline & Strengths & Weaknesses \\
\hline Visibility of system status & $\begin{array}{l}\text { Web page title clearly highlighted showing } \\
\text { the user exactly where he is on the } \\
\text { website. }\end{array}$ & None. \\
\hline $\begin{array}{l}\text { Match between system } \\
\text { and the real world }\end{array}$ & $\begin{array}{llll}\begin{array}{l}\text { Language } \\
\text { enthusiasts }\end{array} & \text { consistent with equestrian } \\
\end{array}$ & $\begin{array}{l}\text { Website has animations that have no relevance to the } \\
\text { site content. }\end{array}$ \\
\hline User control and freedom & None & Relies on the "back" button of the browser \\
\hline Consistency and standards & $\begin{array}{l}\text { Consistent positioning of search bar at the } \\
\text { bottom of the page }\end{array}$ & $\begin{array}{l}\text { Content of the web site does not follow a consistent } \\
\text { structure. } \\
\text { FAE Test [11]: Does not completely comply with web } \\
\text { accessibility requirements with regard to navigation and } \\
\text { Orientation, use of Text Equivalents, Text Styling and } \\
\text { HTML Standards; } \\
\text { W3C Validation [12]: Fails to conform to W3C HTML } \\
\text { standards (18 Errors, } 2 \text { warnings) }\end{array}$ \\
\hline Error prevention & $\begin{array}{l}\text { Minimises chance of getting errors by } \\
\text { restricting search entry to clicking on the } \\
\text { appropriate month. }\end{array}$ & $\begin{array}{l}\text { No independent search method - no errors } \\
\text { Site search requires user typing in search items - } \\
\text { spelling mistakes lead to item not being found. }\end{array}$ \\
\hline $\begin{array}{l}\text { Recognition rather than } \\
\text { recall }\end{array}$ & $\begin{array}{l}\text { Consistent positioning of search bar at the } \\
\text { bottom of the page }\end{array}$ & $\begin{array}{l}\text { It is not clear what the site is offering and it is not } \\
\text { apparent what to do on it } \\
\text { Difficult to navigate }\end{array}$ \\
\hline $\begin{array}{l}\text { Flexibility and efficiency } \\
\text { of use }\end{array}$ & Search organised by month basis - fast & $\begin{array}{l}\text { Search by month only leaves no room for modifying or } \\
\text { refining search query. }\end{array}$ \\
\hline $\begin{array}{l}\text { Aesthetic and minimalist } \\
\text { design }\end{array}$ & Basic consistent page design & $\begin{array}{l}\text { Search results scrolls down beyond the screen - may } \\
\text { hide information inadvertently. } \\
\text { Website exhibits poor fonts and non-contrastive choice } \\
\text { of colours in navigation bar }\end{array}$ \\
\hline $\begin{array}{l}\text { Help users recognize, } \\
\text { diagnose, and recover } \\
\text { from errors }\end{array}$ & None & Offers no help making it difficult for novice users \\
\hline Help and documentation & None & Offers no help making it difficult for novice users \\
\hline
\end{tabular}

The Riding Diary [Figure 2] is a site that allows users to search for equestrian events all over the UK. The fonts used for titles are not distinct from those used for ordinary text. Navigation bars are also affected by lack of contrast. In addition, the site makes little use of white space. All this means that a user visiting the site has to take time to get acquainted with the site. This may result in users quickly moving on to other websites without getting what they were looking for.

Nevertheless, search methods employed by the site are well formatted and easy to understand. Drop down menus are used, which is a good approach as it limits the errors that can occur because the users can only select certain options and won't make any typing errors. However, the user can press the "Go" button without selecting any options and the website simply refreshes the page without issuing any error messages. This will not educate users, and could mean that they continue to make the same mistake. As stated by Ravden and Johnson [13], "Users should be given clear, informative feedback on what actions they have taken and whether these actions have been successful”.

\subsection{The Equine Tourism Website}

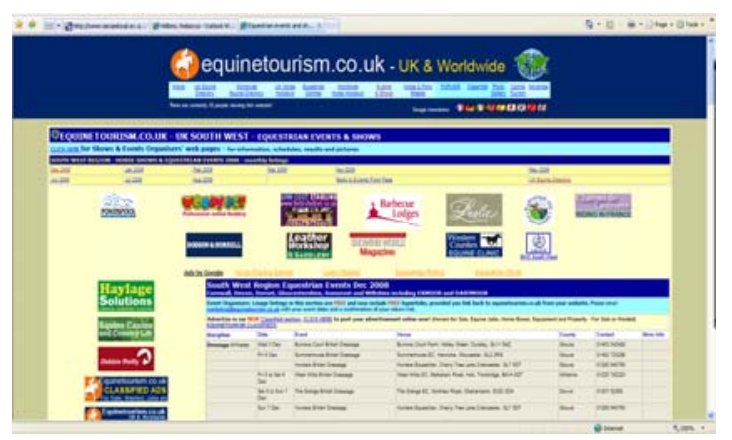

Figure 3. The Equine Tourism Homepage 
Table 3. Qualitative Results for the Heuristic Evaluation of the Riding Diary Website

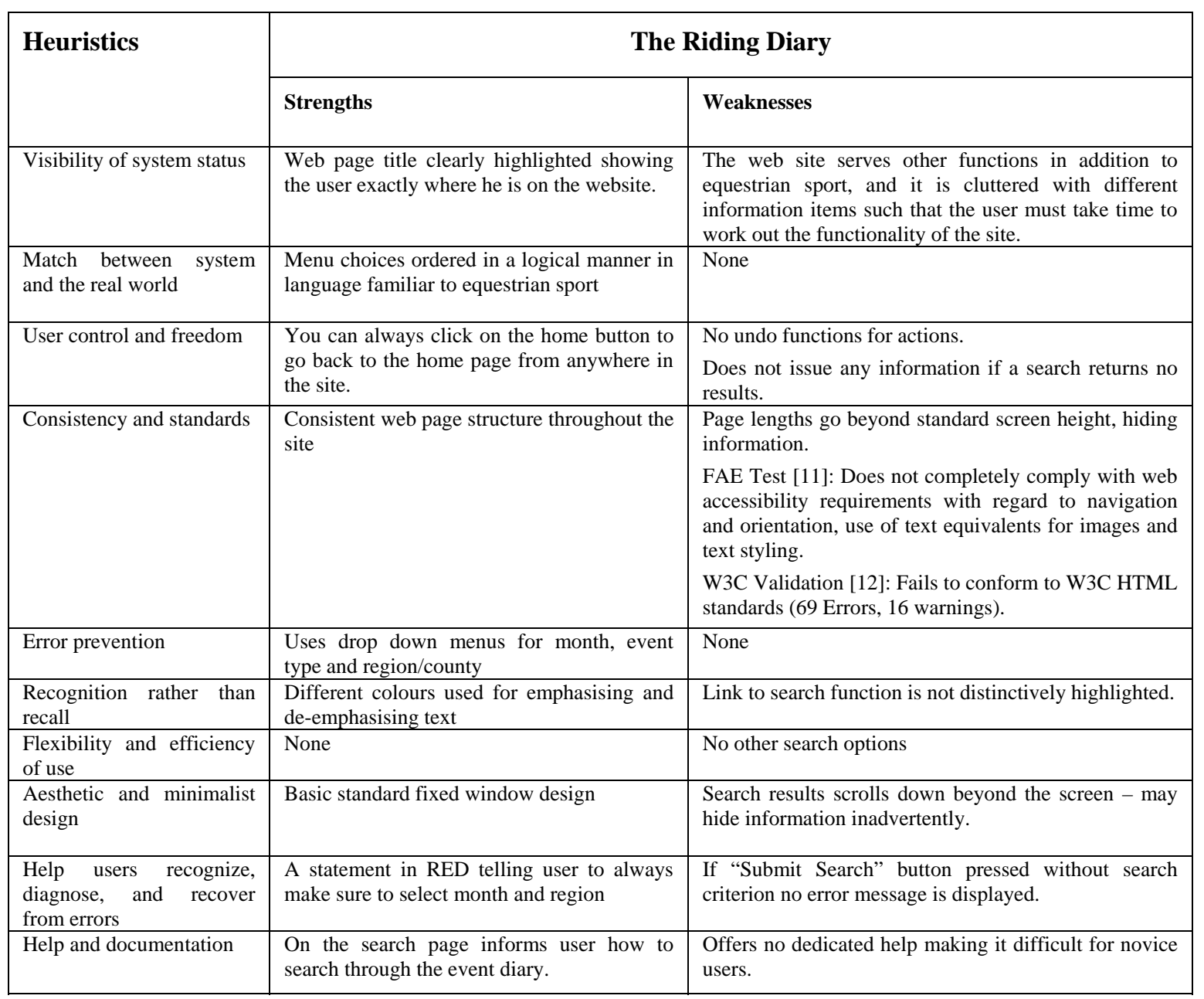

The Equine Tourism website [Figure 3] is not solely about equestrian events. It also offers other equine related choices. The website has a clear title and a good colour scheme. The main part of the homepage includes a lot of links which could bore, confuse and affect the user's attention. Moreover, the homepage extends beyond the screen, meaning that the user must scroll down to see all the displayed information. Most importantly, the search facility appears to be limited as it only allows users to search for events by region or by calendar month. These two search options result in the website displaying a huge table which the user has to scroll through in order to get the required information.

The site is popular with its users once they have gained experience on it. However, for a first time user this is not the case, as he/she would need time to understand the website and learn how to navigate through it.

\subsection{Common Weaknesses}

The following usability aspects were found to be lacking on all three websites:

1. Flexibility and efficiency of use - Poor organisation of search results - should be clearly presented on a page and should not scroll down beyond the screen

2. Flexibility and efficiency of use granularity of search limited to searching events by month, and search is on a county basis - too many unwanted results returned

3. Aesthetic and minimalist design - pages routinely exceed screen display height may hide information inadvertently

4. Help and documentation - no help offered by the websites

5. Recognition rather than recall - pages try to serve multiple functions leading to user confusion 
Table 4. Qualitative Results for the Heuristic Evaluation of the Equine Tourism Website

\begin{tabular}{|c|c|c|}
\hline \multirow[t]{2}{*}{ Heuristics } & \multicolumn{2}{|c|}{ Equine Tourism } \\
\hline & Strengths & Weaknesses \\
\hline Visibility of system status & $\begin{array}{l}\text { Navigation bar at the top; highlighted links in } \\
\text { central window }\end{array}$ & $\begin{array}{l}\text { A cluttered website with too many links and } \\
\text { too much detail }\end{array}$ \\
\hline User control and freedom & $\begin{array}{l}\text { There is always a link back to the Homepage } \\
\text { from any page }\end{array}$ & $\begin{array}{l}\text { Relies on the "back" button of the browser - } \\
\text { no undo button. }\end{array}$ \\
\hline Error prevention & $\begin{array}{l}\text { Minimises chance of getting errors by } \\
\text { restricting search entry to clicking on the } \\
\text { appropriate month. }\end{array}$ & None \\
\hline Recognition rather than recall & $\begin{array}{l}\text { Menu items unambiguously labelled - all } \\
\text { you need to do is to find the menu item }\end{array}$ & Indistinct menu choices. \\
\hline $\begin{array}{l}\text { Help users recognize, diagnose, and } \\
\text { recover from errors }\end{array}$ & $\begin{array}{l}\text { Use of distinct names consistent with } \\
\text { equestrianism helps to reduce errors }\end{array}$ & $\begin{array}{l}\text { No help facilities within web pages or } \\
\text { website }\end{array}$ \\
\hline Help and documentation & None & $\begin{array}{l}\text { No help documentation or instructions within } \\
\text { website }\end{array}$ \\
\hline
\end{tabular}

\subsection{Common Strengths}

Al the three websites were found to possess the following desirable usability aspects:

1. Visibility of system status - Each web page title clearly displayed on top of the web page - enabling user to know which area of the website she/he is currently located

2. Consistency and standards - Web pages on each website had a consistent page layout. Also, on each website the navigation bars were placed on consistent positions on each page.

3. Aesthetic and minimalist design - All the web pages on each of the three websites have a simple architecture

\subsection{Conclusions on Findings}

Finally: Are equestrian sport websites in Devon and Cornwall meeting the usability requirements of their intended audience? All the three websites analysed in this research exhibited significant usability problems which present formidable 
challenges to new and infrequent users and greatly hamper the efficiency and effectiveness of experienced users. This strongly suggests that none of these three websites has been designed and implemented using user-centred design approaches. Since these are the three most popular equestrian sport websites in Devon and Cornwall, our findings strongly suggest that poor usability may be a significant reason why most equestrian sport enthusiasts shun available websites in preference for well established traditional information sources like newspapers, magazines, leaflets and word of mouth. Clearly, usability driven website design would make websites more welcoming to users, thereby encouraging more users to make more use of websites for their informational requirements.

\section{Equestrian Sport Websites Usability Guidelines}

Following our analysis of the three most popular equestrian sport websites in Devon and Cornwall we developed a set of guidelines that can help web developers to build web pages that are more usercentric. Whist these guidelines are specific to search websites like the equestrian sport websites studied in this research, they can also be extended to other websites as well. We have used Nielsen's [7] set of ten heuristics as a template around which to develop the guidelines.

\section{Visibility of system status}

1. The homepage: This should clearly indicate the functionality of the site, yet look attractive and download fast to keep the users interested. According to Nielsen [14], the first immediate goal of any homepage is to answer the questions: "Where am I?", and "What does this site do?"

2. Feedback: The website should provide clear informative feedback to users so that they are continuously aware of where they are in the web site, what actions they have taken, whether these actions have been successful and what actions should be taken next.

\section{Match between system and the real world}

1. Choice of Names and Acronyms: The website should use titles that are relevant and meaningful to the equestrian sport community. This will make it more accessible to the target audience since titles and headings are often used as the main reference to the pages.

2. Length of Headings and Titles: Where possible, headings and titles should be no more than three in line, with the suggestion by Nielsen [14] that it is "best to aim titles between two and six words" if good usability is to be achieved.

\section{User control and freedom}

1. Interactivity: Give prominence to the search functionality to encourage the user to experiment and learn through activity. Interactivity improves the user's sense of fun and satisfaction, which, in turn, improves the user's productivity when using the website [15].

2. Response time: Use images sparingly to reduce the response time of the website since web pages with images take long to download. One tenth of a second is about the limit for having the user feel that the system is reacting instantaneously, and users often associate poor response time with poor usability, and will often move on to other sites [14].

\section{Consistency and standards}

1. Compliance with World Wide Web Consortium (W3C) Standards: The website should comply with web application development standards. Complying with web application development standards improves user experience, in addition to simplifying maintenance and making the website compatible with more browsers and Internet-aware devices [16].

2. Compliance with Web Content Accessibility Guidelines (WCAG): This ensures that people with disabilities are able to access the website. This is important since equestrian sport is a spectator family-friendly sport. Incidentally, making the web page accessible to people with disabilities helps to improve the website's usability for everyone as well [17].

3. Website consistency: Maintain consistency throughout the website. Website consistency greatly increases the speed of learning and improves the efficiency and effectiveness of human-computer interaction, thereby significantly reducing the likelihood of errors [13]. For instance, all the web pages on the website should have the same page layout and they should have the same look and feel as far as possible. Ideally, all the components that perform the same function should occupy the same position on each web page throughout the website, and identical tasks 
should be carried out in the same manner on each web page.

\section{Error prevention}

1. Search Design: Wherever possible, use drop down menus to specify users' search criteria. Most people have difficulties choosing appropriate search queries [18]. Consequently, if users have to type in their search queries, they may end up getting information that is not relevant to their requirements, and this may lead them to waste time refining the queries to ensure that they get the right information.

\section{Recognition rather than recall}

1. Positioning and sizing navigation buttons: Position navigation buttons in obvious places on each web page. Use size to show the relative importance of each button. For instance, with regard to implementing the search functionality the "Submit Search" button is the most important button on the web page since it is the one used for submitting the relevant search criteria to the web site database to retrieve the information required by the user. In this case the "Submit Search" button should be larger than any of the other buttons on the site, and should be prominently located.

2. Link Labels: Link labels should be unambiguous to enable users to accurately predict where they will end up if they click on a link.

3. Style and colour coding: Style and colour coding should be consistent with general use on other web pages on the Internet.

\section{Flexibility and efficiency of use}

1. Search results: All the results that are shown should be valid to their search query. This will mean that irrelevant information will not be shown, thus decreasing the time that the user has to spend reading through the results.

2. Feedback: The amount of feedback given to users should strike a balance between being sufficient for novice users and not being irritating to experienced users [13].

\section{Aesthetic and minimalist design}

1. Visual Design of Web pages: Web pages should be simple, clear and easy to understand. In a survey on usability requirements for disabled people by
Gappa \& Nordbrock [19] all the test participants stated that a clear and simple design was very important.

2. Navigation buttons: Limit the number of the main navigation buttons on a web page to no more than six, and associate each of the navigation buttons with easy-toremember text. This is in line with the findings by Gappa \& Nordbrock [19] on usability requirements for disabled people.

Help users recognize, diagnose, and recover from errors

1. Information on errors: Explanatory information accompanying error notification should be concise and sufficient enough to ensure that users recover from these errors and are able to continue with their searches.

\section{Help and documentation}

1. Help information: Sufficient help should be provided to help new users to get acquainted with the web site. This helps in the new user's learning process and helps to ensure that new users gain sufficient skills to use the web site efficiently and effectively.

\section{Evaluation of Proposed Guidelines Using Prototyping}

A prototype equestrian sport website was developed using the website development guidelines proposed in this paper. User tests were then used to compare this prototype against the Web South West website. We chose the Web South West website over the Riding Diary and Equine Tourism websites because it is currently the most popular equestrian sport website in Devon and Cornwall at the present moment. Our assumption is that since it is currently the most popular, then, by default, it has the best overall usability features that appeal to the targeted user group.

For the user tests, we chose twelve people who had no prior exposure to and no knowledge of both our prototype website and the Web South West website. The twelve participants ranged in age from 13 to 56 and their standard of education ranged from secondary school, college level to university level education. We opted for twelve participants in accordance with Nielsen and Landauer's [20] suggestion that in a usability test twelve to fifteen participants are sufficient to determine all the usability problems. 
For each website, each participant filled out a questionnaire, and carried out two search tasks under observation. Incorporating tasks into the evaluation alongside the questionnaires enables the test participants to be exposed to as many aspects of the website as possible. This is necessary if the participants are to comment usefully, and in detail, on the website's specific features, problems, strengths and deficiencies [13].

The two tasks that participants carried out under observation were:

1. Go to the website homepage and find a hunter trial to go to in Cornwall on the $15^{\text {th }}$ March 2009. Where is it?

2. Stay on the site and list all the events that are occurring on the $13^{\text {th }}$ April 2009.

With regard to the first task, all the test participants managed to find the correct answer in less than a minute using our prototype website. In comparison, all the participants took much longer to find the correct answer using the Web South West website. For instance, one participant took five minutes to find the answer, whilst another took ten minutes and only managed to do so after soliciting for help.

With regard to task two there were actually four events occurring on the $13^{\text {th }}$ April 2009. All participants managed to find all the four answers on our prototype website. This is in contrast to the Web South West website where only one participant managed to find all the four events, with the rest managing to find three events out of four. This may suggest that our website is better organised and has a clearer navigational structure than the Web South West website.

The questionnaire was divided into two parts; the first part evaluated the participants' computer literacy whilst the second part evaluated the usability of the two websites under evaluation, namely our prototype website and the Web South West website.

When test participants were asked for a self evaluation of their own computer literacy, three rated themselves as very good, five as good, two as average, one as poor and the final participant rated himself as having very poor computer literacy skills. This distribution, typified by a significant number of computer literate people and others with little or no computer literacy, is consistent with the target user group, which comprises computer-savvy young people as well as the elderly who may never had the opportunity or inclination to improve their computing skills. The evaluation also established that eleven of the participants have been using computers for more than three years, whilst one had less than three years of computer use. Seven of the participants use the Internet for more than five hours per week with only one stating that he accessed the Internet for less than one hour a week.
These finding suggest that the target audience are generally computer literate and quite familiar with the Internet.

The second part of the questionnaire was to evaluate usability. It consists of nineteen questions per website, which fall into these four categories; Visual clarity, consistency, informative feedback and aesthetic appeal.

With regard to visual clarity, a good website should make the screen appear uncluttered and enable the user to find the required information quickly and easily. It should also draw the user's attention to important information and enable users to see and read information on the screen clearly and effortlessly [13].

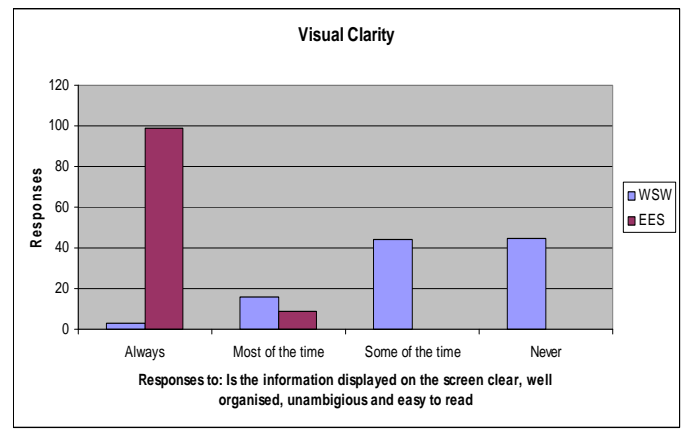

Key: WSW - Web South West

EES - Prototype Website

Figure 4: Test participants' responses to the queries on the two websites' visual clarity, expressed as a percentage of total responses.

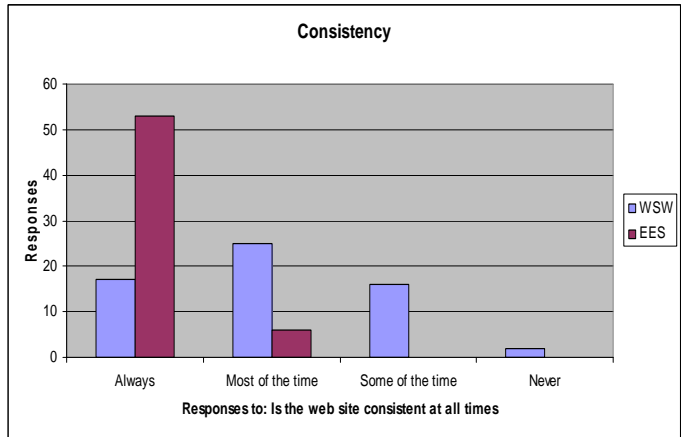

Key: WSW - Web South West EES - Prototype Website

Figure 5: Test participants' responses to the queries on the two websites' consistency, expressed as a percentage of total responses.

The responses for each visual clarity response category were summed together and expressed as a percentage of the total number of responses [Figure 4]. The graph clearly suggests that the participants perceived our prototype website to have more 
superior visual clarity when compared to the Web South West website. For instance, whilst responses tended to be predominantly positive for our website, they were mostly negative for the Web South West website.

Again, with regard to consistency, test participants rated our website more highly than the Web South West website, as shown by the totalled percentage responses in Figure 5.

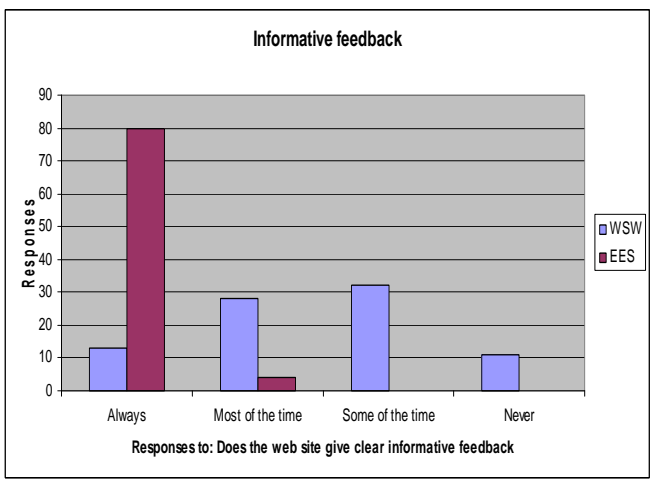

Key: WSW - Web South West EES - Prototype Website

Figure 6: Test participants' responses to the queries on the quality of the two websites' feedback, expressed as a percentage of total responses.

Figure 6 shows the totalled percentage responses to the informative feedback section in the questionnaire. From the graph it is clear that most test participants thought that our website always offers informative feedback. In contrast, responses for the WSW website were fairly evenly distributed across all the categories. Evidently, our site is better suited at letting users learn and understand how to interact with it better than the WSW website.

Finally test participants were asked how they would rate each website overall. All the test participants felt that our prototype website was very satisfactory. In contrast, the Web South West website received poor overall ratings, with no positive responses at all, and with half of the participants describing it as moderately unsatisfactory, and a further one third describing it as very unsatisfactory.

On the basis of this assessment it can be concluded that our prototype website outperformed the Web South West website on all the aspects that were evaluated. Both websites were constructed using the same Web technologies, and, possibly, the only difference was that the design and development of our website was entirely driven by usability requirements.

\section{Concluding Remarks}

The findings reported in this paper suggest that, to a large extent, equestrian sport websites in Devon and Cornwall suffer from usability problems. As demonstrated in the discussion on the user test results, these usability problems have the effect of discouraging website use. If the owners of these equestrian sport websites are viewed as business entities chasing the Internet advertising dollar in the leisure pursuit industry, we can conclude that poor usability presents a very real and significant monetary cost, especially in largely rural areas like Devon and Cornwall where tourism and leisure pursuits represent a significant part of the local economy. However, as this paper clearly shows, poor usability is largely avoidable. For instance, the guidelines proposed in this paper indicate that website usability can be easily improved with minimal costs. Therefore, given the ease with which website usability can be improved, and the huge financial implications for neglecting usability, we propose that usability should seize to be just a topic discussed by technical personnel. Rather, usability should feature highly in the minds of those tasked with leading and managing organisations - all organisations since almost all organisations have an Internet presence. Usability should be a byword for each and every employee in an organisation, much the same as quality assurance and profitability are part and parcel of the everyday vocabulary in all successful manufacturing and service organisations.

\section{References}

[1] Ipsos Mori, Accessing the Internet at Home - A Quantitative and Qualitative Study Among People without the Internet at Home, 2009.

Available at: http://www.ofcom.org.uk/research/ telecoms/ reports/bbresearch/bbathome.pdf (Accessed: 20 Feb 2010).

[2] W.H. Dutton, E.J. Helsper and M.M. Gerber, The Internet in Britain: 2009, Oxford Internet Institute, University of Oxford, 2009.

[3] J. Nielsen, Usability Engineering, San Francisco: Morgan Kaufmann, 1994.

[4] International Organization for Standardization, ISO 9241-11:1998(E): Ergonomic requirements for office work with visual display terminals (VDTs) Part 11: Guidance on usability, 1998.

[5] B. Shneiderman, Designing the User Interface: Strategies for Effective Human-Computer 
Interaction, Reading, Mass., Harlow: Addison Wesley Longman, 1998.

[6] J. Nielsen, Discount Usability for the Web, 1997. Available at: http://www.useit.com/papers/ web_discount_usability.html (Accessed: 20 Feb 2010).

[7] J. Nielsen, Ten Usability Heuristics, 2005. Available at: http://www.useit.com/papers/ heuristic/heuristic_list.html (Accessed: 20 Feb 2010).

[8] Web South West. Available at: http://www.websouthwest.co.uk/ (Accessed: 6 March 2009).

[9] Equine Tourism. Available at: www.equinetourism.co.uk (Accessed: 20 March 2009)

[10] The Riding Diary. Available at www.ridingdiary.co.uk (Accessed: 20 March 2009)

[11] Illinois Center for Information Technology and Web Accessibility, Functional Accessibility Evaluator 1.0.3, Available at: http://fae.cita.uiuc. edu/ (Accessed: 20 Feb 2010).

[12] The World Wide Web Consortium, Markup Validation Service, Available at: http://validator. w3.org/ (Accessed: 20 Feb 2010).

[13] S. J Ravden and G. I. Johnson, Evaluating Usability of Human-Computer Interfaces: A Practical Method, Chichester, England: Wiley, 1989.

[14] J. Nielsen, Designing Web Usability, Indianapolis, IN: New Riders Publishing, 2000.

[15] H. Teo, L. Oh, C. Liu, and K. Wei, “An empirical study of the effects of interactivity on web user attitude", Human-Computer Studies, 2002, pp. 281-305.

[16] J.Veen, The Business Value of Web Standards, 2003. Available at: http://www.adaptivepath.com/ ideas/essays/archives/000266.php (Accessed: 24 Feb 2010).

[17] Illinois Center for Information Technology and Web Accessibility, HTML Best Practices, 2008. Available at: http://html.cita.illinois.edu/ (Accessed: 24 Feb 2010).

[18] R.Nordlie, “ "User Revealment” - A Comparison of Initial Queries and Ensuing Question Development in Online Searching and in
Human Reference Interaction”, in Proceedings of SIGIR99, Berkeley, CA., 1999, pp. 11-18.

[19] H. Gappa, and G. Nordbrock, “Applying Web accessibility to Internet portals”, Universal Access in the Information Society, 2004, pp. 80-87.

[20] J. Nielsen and T. K. Landauer, “A mathematical model of the finding of usability problems", in Proceedings of INTERCHI 93, New York, NY: ACM, 1993, pp.206-213. 